\title{
MULTIDISCIPLINARY TREATMENT OF A PATIENT WITH DILACERATED AND TRANSPOSED TEETH
}

\author{
Sanaz SADRY ${ }^{*}{ }^{*}$, Selin KORAMAZ ÜSTÜNAY ${ }^{1}$, Esra YÜCE ${ }^{2}$, Didem ÖNER ÖZDAŞ ${ }^{3}$ \\ ${ }^{1}$ Department of Orthodontics, Faculty of Dentistry, Istanbul Aydin University, 34295, Istanbul, Turkey \\ ${ }^{2}$ Department of Oral, Maxillofacial Surgery, Faculty of Dentistry, Istanbul Aydin University, 34295, Istanbul, Turkey \\ ${ }^{3}$ Department of Pediatric dentistry, Faculty of Dentistry, Istanbul Aydin University, 34295, Istanbul, Turkey
}

\begin{abstract}
Tooth transposition can be described as interchange in position of two adjacent permanent teeth in the same quadrant. A case with a maxillary permanent dilacerated central and tranposition of canine-lateral incisor, treated with forced eruption and piezosurgical technique to shorter treatment time. Treatment is challenging for both orthodontists and oral surgeons. Using conebeam computed tomography is necessary to correct localization and treatment planning. In this case report, successful eruption of the high vestibule dilacerated central incisor and canine transposition was performed so that the lateral incisor could be preserved in canine position. After orthodontic treatment, the patient smile esthetics and occlusion were significantly improved.
\end{abstract}

Keywords: Dilaceration, Orthodontics, Piezosurgery, Eruption

*Corresponding author: Department of Orthodontics, Faculty of Dentistry, Istanbul Aydin University, 34295, Istanbul, Turkey

E mail: sanazsadry@hotmail.com (S. SADRY)

Sanaz SADRY (iD) https://orcid.org/0000-0002-2160-0908

Selin KORAMAZ ÜSTÜNAY (iD) https://orcid.org/0000-0002-7632-8788

Esra YÜCE (iD) https://orcid.org/0000-0002-8026-9522

Received: February 01, 2021

Accepted: March 22, 2021

Didem ÖNER ÖZDAŞ

https://orcid.org/0000-0002-0112-1539

Published: September 01, 2021

Cite as: Sadry S, Korkmaz Üstünay S, Yüce E, Öner Özdaş D. 2021. Multidisciplinary treatment of a patient with dilacerated and transposed teeth. BSJ Health Sci, 4(3): 293-295.

\section{Introduction}

Dilaceration can be described as an angulation of crown or root. Usually dilacerated maxillary incisors have crown directed superior and labially. Treatment of dilaceration depends on the degree of angulation, patient's approval and tooth position (Tak and MengAnn, 2004).

Tooth transposition can be described as interchange in position of two adjacent permanent teeth in the same quadrant. Transposition happens usually between the maxillary canine and first premolar and occasionally between the maxillary canine and lateral incisor (Peck et al., 1993).

In this case report, we present a patient to demostrate high vestibule dilacerated maxillary left central incisor and transposed maxillary left canine. It was diagnosed by cone beam computed tomography (CBCT) and treated with piezosurgical device to accelerate eruption of dilacerated tooth to conclude the required correction.

\section{Case Report}

A 13-year- old boy came to the orthodontic department of the Istanbul Aydin University with the chief complaint of maxillary left dilacerated central incisor which was nonerupted exactly and transposition between canine and lateral incisor. He had no systemic problem with no history of dental trauma. On extraoral examination (Figure 1) there was unaesthetic appearance by malpositioned teeth and space between anterior teeth while smiling. In intraoral examination, there was Class I molar relationship with a complete transposition of the maxillary left canine and lateral incisor, $2 \mathrm{~mm}$ overjet and $5 \mathrm{~mm}$ overbite. His maxillary dental midline was deviated to the left because of dilacerated and high vestibule central and left canine's transposition.

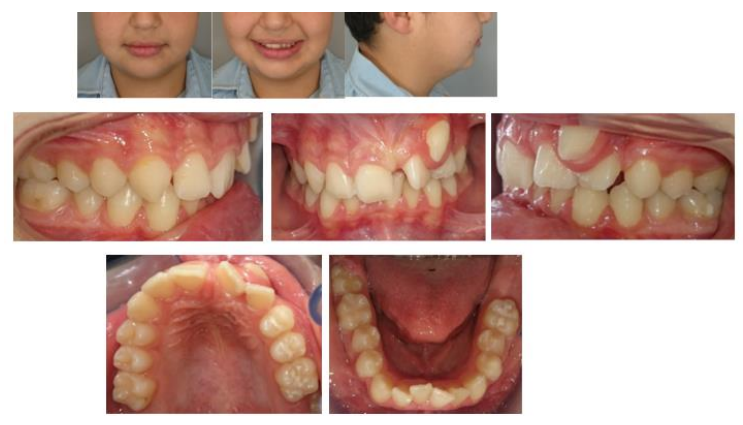

Figure 1. Pre-treatment intra and extraoral photographs of the patient.

Lateral cephalometric assessment (Figure 2) showed a Class I skeletal pattern with normally inclined incisors. The cephalometric measurements are summarized in Table 1. The purpose of treatment was to save transposed the maxillary canine into lateral to establish functional Class I molar and canine reletionships, to correct the maxillary dental midline, and to make an esthetic smile with build ups for maxillary canine and lateral. 

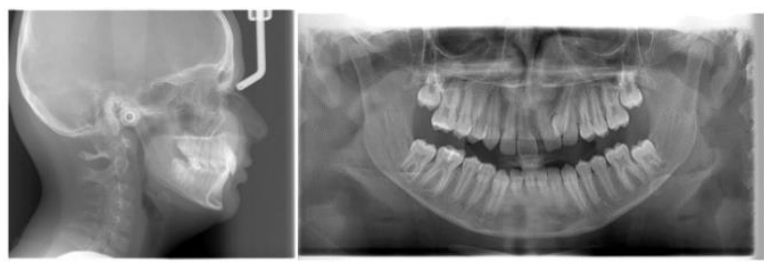

Figure 2. Pre-treatment lateral cephalometric and panaromic radiograph of the patient.

Table 1. Pre-treatment and post-treatment lateral cephalometric measurement

\begin{tabular}{|c|c|c|}
\hline $\mathrm{CM}$ & Pretreatment & Posttreatment \\
\hline SNA $\left(^{\circ}\right)$ & $85^{\circ}$ & $85^{\circ}$ \\
\hline $\operatorname{SNB}\left({ }^{\circ}\right)$ & $81^{\circ}$ & $81^{\circ}$ \\
\hline $\operatorname{ANB}\left({ }^{\circ}\right)$ & $4^{\circ}$ & $4^{\circ}$ \\
\hline $\operatorname{SND}\left({ }^{\circ}\right)$ & $77^{\circ}$ & $77^{\circ}$ \\
\hline 1-NA(mm) & $2 \mathrm{~mm}$ & $5 \mathrm{~mm}$ \\
\hline $1-\mathrm{NA}\left({ }^{\circ}\right)$ & $16^{\circ}$ & $16^{\circ}$ \\
\hline 1-NB(mm) & $5 \mathrm{~mm}$ & $6 \mathrm{~mm}$ \\
\hline $1-\mathrm{NB}\left({ }^{\circ}\right)$ & $25^{\circ}$ & $27^{\circ}$ \\
\hline İnterincisal angle $\left(^{\circ}\right)$ & $144^{\circ}$ & $135^{\circ}$ \\
\hline Po-NB(mm) & $1 \mathrm{~mm}$ & $1 \mathrm{~mm}$ \\
\hline Sn-GoGn $\left({ }^{\circ}\right)$ & $29^{\circ}$ & $31^{\circ}$ \\
\hline $\mathrm{A}-\mathrm{N}(\mathrm{mm})$ & 1 & 1 \\
\hline Pg-N (mm) & -4 & -4 \\
\hline Co-A (mm) & 92 & 92 \\
\hline Co-Gn (mm) & 108 & 108 \\
\hline ANS-Me (mm) & 59 & 59 \\
\hline MP-FFH $\left({ }^{0}\right)$ & 26 & 26 \\
\hline Ba-N/PTM-Gn $\left({ }^{0}\right)$ & 92 & 92 \\
\hline Mand inc-A (mm) & 4 & 6 \\
\hline Max inc-APg $(\mathrm{mm})$ & 1 & 3 \\
\hline $\mathrm{Na}-\mathrm{Pg} / \mathrm{FFH}\left({ }^{0}\right)$ & 88 & 90 \\
\hline
\end{tabular}

$\mathrm{CM}=$ cephalometric measurement, $\mathrm{SN}=$ plane between the anatomical points Sella and Nasion, SNA, SNB= angle between $\mathrm{SN}$ and plane between Nasion- $\mathrm{A}, \mathrm{B}$ point, $\mathrm{ANB}=$ angle between the planes Nasion-A point and Nasion-B point.

A standard $0.016 \times 0.022$ " edgewise appliance was placed in maxillary arch. An open coil was placed between the right central incisor and first premolar to create space. Piezosurgical micro-saw assisted corticotomy was performed to accelerate and to activate the forced eruption of upper left central incisor (Figure 3). The surgery including elevation of a full-thickness flap and removal of interdental alveoler cortical bone (Kole, 1959).

After the flap removing, mesiodistal width of the incisors guided the vertical bone cuts. The vertical cuts of corticotomy were performed from mesial and distal sides of the left upper central and canine through the entire thickness of cortical layer $2 \mathrm{~mm}$ beyond the apices of the teeth. The incision site was primarily closed with a $3 / 0$ silk suture. After the operation, the patient was given analgesic (275 mg Naproxen Sodium $-3 \times 1$ ), antibiotic (875 mg Amoxicillin, $125 \mathrm{mg}$ Clavulonic acid $-2 \times 1$ ) and antiseptic mouthwash $(0.3 \%$ Chlorhexidinglukonate $-3 \times$
1) and how long it used for the patient. They sutur 1 week after the surgical procedure. One week after the corticotomy, 25-30 gr force was applied to the tooth and activated every 2 weeks for 2 months (Wilcko et al., 2001). After opening enough space for the canine, the transposition was preserved and the canine moved to the new position in the arch. Class I molar relationship and ideal overjet-overbite were established (Figure 4). After treatment, skeletal cephalometric values were almost stable whereas incisor relationships and values were improved (Table 1). The bands and brackets were removed. After restorative treatments, a new clear overlay was prepared for retention (Figure 5). Radiographic assesments showed no lesion, bone loss or root resorption (Figure 6).

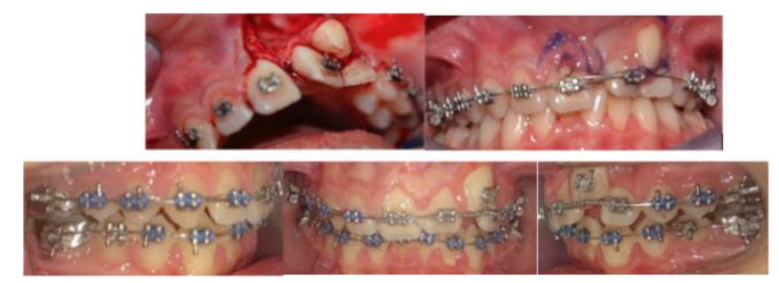

Figure 3. Post-operative intra oral photographs of the patient.

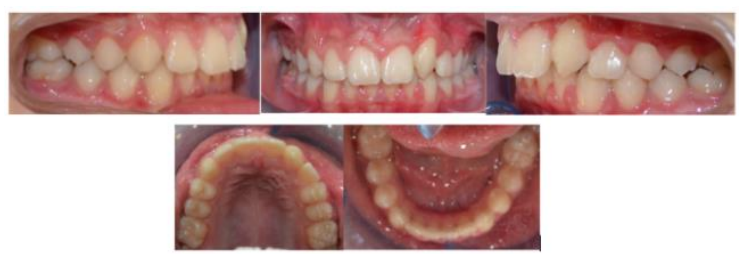

Figure 4. Post treatment after debonding.

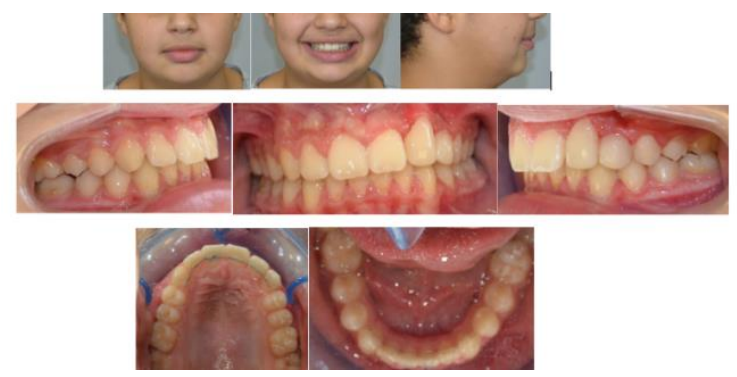

Figure 5. Post-treatment extra and intra-oral photographs of the patient.

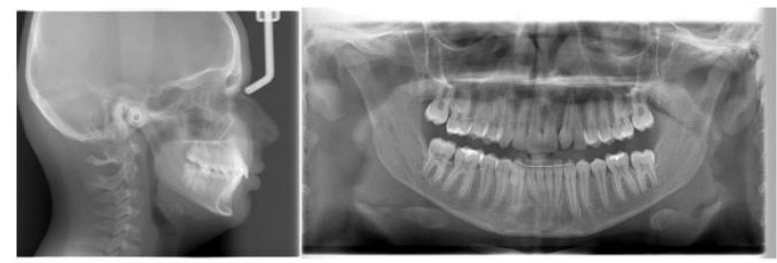

Figfure 6. Post- treatment lateral cephalometric and panoramic radiograph of the patient.

\section{Discussion}

In diverse studies, damaged anterior deciduous teeth from unwanted force changed the development of 
permanent teeth (Locks et al., 2000). This situation contains anomalies that abnormal curve between the crown and the root such as root dilaceration. Depending on the degree of dilaceration and localization of the tooth, effective treatment modality is light force orthodontic traction with surgical exposure and moving the tooth into normal occlusion, although different treatment alternatives are found in the literature (Agnihotri et al., 2006). Orthodontic treatment with extraction of affected tooth can be a treatment choice of these malocclusions. The timing of forced eruption of dilacerated tooth can be affected by the patient's oclusion discrepancy, root apex position, esthetics, periodontal support, age and cooperation (Hsieh et al., 2005). In the current report, we assesed these factors for satisfactory results. To move the dilacerated tooth, angulation between root and crown is important for good prognosis. A bracket was attached to the central incisor after piezosurgical intervention. An incision was performed in the buccal vestibular area followed by piezosurgical knife to the buccal cortical bone. Corticotomy procedure, allowed the resorption/deposition cellular process to proceed in same bone and reduces the bone in this way. However, tooth movement after a corticotomy should be applied for at least 2 weeks and decreases the risk of root resorption. This process leading to less hyalinization of the PDL on the alveoler wall while rapid alveoler bone reaction in the bone marrow cavities (Reitan, 1947; Plion et al., 1996). In the current case report, tooth movements were started 2-weeks after corticotomy and total treatment time was less than 1-year. The force was applied with figurated tie between the bracket and the $0.016 \times 0.022$ " stainless steel arch wire. Canine-lateral incisor transpositon preserved and later transformation of the canine into lateral incisor was completed. The canine movement in this case was not hard, because the tooth was already positioned in mesial side, as known as incomplete transposion (Chaushu et al., 2003). The canine shape was restorated for more esthetic appearance. In this patient lateral contact in functional occlusion was obtained by maxillary lateral incisor with esthetic compromises. For this case, treatment was accomplished in only 8 months. The patient has been followed for 1 year, satisfactory occlusal and aesthetic results have been secured.

\section{Conclusion}

Treatment of maxillary dilacerated incisor and a complete canine-lateral transposition is a complicated challenge for orthodontists. A multidisciplinary approach with orthodontic, oral surgery and restorative department examinations are very important. In this patient functional and esthetic treatment results were obtained with convenient direction of orthodontic force with guidance of CBCT and piezosurgical support.

\section{Author Contributions}

All authors have equal contribution and all authors read and approved the final manuscript.

\section{Conflict of Interest}

The authors declare that there is no conflict of interest.

\section{Ethical Approval/Informed Consent}

Necessary information was given to the family and an informed consent form was obtained.

\section{Acknowledgements}

The data that support the findings of this study are available from the corresponding author upon reasonable request from sanazsadry@aydin.edu.tr

\section{References}

Agnihotri A, Marwah N, Dutta S. 2006. Dilacerated unerupted central incisor: a case report. J Indian Soc Pedod Prev Dent, 24: 152-154.

Chaushu S, Zilberman Y, Becker A. 2003. Maxillary incisor impaction and its relationship to canine displacement. Am J Orthod Dentofacial Orthop, 124: 144-150.

Hsieh TJ, Pinskaya Y, Roberts WE. 2005. Assessment of orthodontic treatment outcomes: early treatment versus late treatment. Angle Orthod, 75: 162-170.

Kole H. 1959. Surgical operations on the alveolar ridge to correct occlusal abnormalities. Oral Surg Oral Med Oral Pathol, 12: 515-552.

Locks A, Ritter DE, Morona AR, Haertel GB, Ribeiro GLU, Menezes LM. 2000. Orthodontic-surgical treatment of a dilacerated maxillary central incisor-clinical report. R Dental Press Ortodon Ortop Facial, 5: 75-79.

Peck L, Peck S, Attia Y. 1993. Maxillary canine-first premolar transposition,associated dental anomalies and genetic basis. Angle Orthod, 63: 99-110.

Pilion JJGM, Kuijpers-Jagtman AM, Maltha JC. 1996. Magnitude of orthodontic forces and rate of bodily tooth movement: an experimental study in beagle dogs. Am J Orthod Dentofacial Orthop, 110: 16-23.

Reitan K. 1947. Continuous bodily tooth movement and its histological significance. Acta Odont Scand, 6: 115-144.

Tak CM, Meng-Ann OM. 2004. Orthodontic-surgical management of an impacted dilacerated maxillary central incisor: a clinical case report. Pediatr Dent, 26: 341-344.

Wilcko WM, Wilcko MT, Bouquot JE. 2001. Rapid orthodontics with alveolar reshaping: two case reports of decrowding. Int J Perio Restor Dent, 21: 9-19. 